\title{
MECANISMOS PARA POTENCIALIZAÇÃO DA PROTEÇÃO DO PATRIMÔNIO CULTURAL ARQUITETÔNICO NO MUNICÍPIO DE BELO HORIZONTE
}

\section{MECHANISMS FOR THE POTENTIALIZATION OF THE PROTECTION OF ARCHITECTURAL CULTURAL HERITAGE IN THE MUNICIPALITY OF BELO HORIZONTE}

\section{Renato Leal Penido Fonseca ${ }^{1}$}

\section{Resumo}

Este estudo trata dos mecanismos para potencialização da preservação do patrimônio cultural arquitetônico no município de Belo Horizonte. Observou-se que, embora o instituto do tombamento seja utilizado para proteção dos bens culturais arquitetônicos, por vezes mostrase ineficiente. Na busca por maior efetividade da proteção do patrimônio cultural, foram criados instrumentos para mitigação dos custos de manutenção das edificações e compensação financeira em razão da limitação do exercício do direito de propriedade. Além desses instrumentos, analisou-se o programa "Adote um Bem Cultural", uma iniciativa de cooperação entre o setor privado e a Administração Pública municipal.

Palavras-chave: Patrimônio cultural, tombamento, medidas compensatórias, isenção de IPTU, transferência do direito de construir

\section{Abstract}

The present work discusses the mechanisms for enhancing the preservation of architectural heritage in the city of Belo Horizonte, Minas Gerais, Brazil. It has been observed that, although the real estate protection institute is used for protection of architectural heritage, sometimes it might be inefficient. In the search for greater effectiveness of the protection of architectural heritage, instruments were created to mitigate the costs of building maintenance and financial compensation due to the limitation to exercise property rights. In addition to these instruments,

\footnotetext{
${ }_{1}^{1}$ Advogado. Mestre em Direito Ambiental e Desenvolvimento Sustentável pela Escola Superior Dom Helder Câmara. Membro do Grupo de Pesquisa "Por uma justiça ambiental: estudos de Filosofia do Ambiente e de Ética Ambiental para um novo Direito Ambiental". Atuação nas áreas de Direito Ambiental, patrimônio cultural, sustentabilidade e governa. E-mail: renato@renatopenido.com.br
} 
the program called "Adote um Bem Cultural", a cooperation initiative between the private sector and the municipal public administration, was also analyzed.

Keywords: Heritage, real estate protection, costs mitigation, remission of property tax, transfer of building rights

\section{INTRODUÇÃO}

A Constituição da República de 1988 tratou sobre proteção do patrimônio cultural em seu art. 216, dada sua relevância na preservação da memória, identidade e ação dos diversos grupos formadores da sociedade brasileira. Anterior à Constituição da República de 1988, o Decreto-Lei no 25/37, mais conhecido como a Lei do Tombamento, sistematizou a proteção do patrimônio cultural, especificamente, os bens de natureza material.

Embora o instituto do tombamento constitua um importante instrumento para a salvaguarda do patrimônio cultural arquitetônico, em determinados casos esse mecanismo se revela pouco eficiente. Alguns proprietários de edificações tombadas as abandonam, demolem, danificam deixam de promover obras de conversação, com objetivo de inviabilizar a restauração dos imóveis e, por consequência, o desfazimento do tombamento. Ante esse quadro, o município de Belo Horizonte institui medidas compensatórias a fim de estimular os proprietários à preservação do patrimônio cultural imobiliário. Além das medidas de compensatórias, foi criado o programa de colaboração para salvaguarda do patrimônio cultural do município de Belo Horizonte.

O presente trabalho investigou a criação das medidas compensatórias de isenção de Imposto Predial e Territorial Urbano (IPTU), a Transferência do Direito de Construir, como instrumentos de potencialização da preservação do patrimônio cultural arquitetônico, no município de Belo Horizonte, consoante às diretrizes urbanísticas do Estatuto da Cidade.

Por fim, analisou-se o programa "Adote um bem Cultural", criado pelo município de Belo Horizonte, uma iniciativa de cooperação entre o setor privado e a Administração Pública para a proteção, preservação e promoção dos bens culturais.

Para consecução deste estudo, foram consultadas a Constituição da República de 1988, legislações federais e municipais, artigos científicos e doutrinas. 


\section{REFLEXOS NORMATIVOS DA PROTEÇÃO CONSTITUCIONAL DO PATRIMÔNIO CULTURAL}

A proteção do patrimônio cultural recebeu tratamento em diversos diplomas legais, tanto no plano infraconstitucional quanto constitucional. No entanto, a sistematização proposta pelo Decreto-Lei no 25, de 30 de novembro de 1937, abordou de modo abrangente a proteção do patrimônio cultural material, instituindo a figura do Tombamento (REIS\&FONSECA, 2016).

Anterior à Constituição da República de 1988 e por ela recepcionado, o Decreto-Lei no 25, de 30 de novembro de 1937, comumente conhecido como a Lei do Tombamento, dispôs sobre a proteção do patrimônio histórico e artístico brasileiro. O conceito introduzido pelo Decreto-Lei n² 25/37, em seu artigo 1ำ, caput, privilegiou a proteção do patrimônio material, sejam eles móveis ou imóveis, condicionando-os a um caráter de excepcionalidade.

Art. 1o - Constitue (sic) o patrimônio histórico e artístico nacional o conjunto dos bens móveis e imóveis existentes no país e cuja conservação seja de interêsse (sic) público, quer por sua vinculação a fatos memoráveis da história do Brasil, quer por seu excepcional valor arqueológico ou etnográfico, bibliográfico ou artístico.

Posteriormente, a Constituição da República de 1988, ao sistematizar a proteção do patrimônio cultural no art. 216, caput, ampliou e relativizou o conceito patrimônio histórico e artístico, introduzido pelo Decreto-Lei no 25/37, adotando a expressão patrimônio cultural. A Constituição da República de 1988 incorpora a ideia de cultura como referencial, preterindo a de história, expandindo esta salvaguarda ao patrimônio de natureza imaterial. A excepcionalidade como requisito para caracterização do bem como patrimônio cultural cede espaço aos referenciais identidade, ação e memória dos diferentes grupos formadores da sociedade brasileira. Dispõe o art. 216 da Constituição da República de 1988:

Art. 216. Constituem patrimônio cultural brasileiro os bens de natureza material e imaterial, tomados individualmente ou em conjunto, portadores de referência à identidade, à ação, à memória dos diferentes grupos formadores da sociedade brasileira, nos quais se incluem:

I - as formas de expressão;

II - os modos de criar, fazer e viver;

III - as criações científicas, artísticas e tecnológicas;

IV - as obras, objetos, documentos, edificações e demais espaços destinados às manifestações artístico-culturais;

$\S 1$ o O Poder Público, com a colaboração da comunidade, promoverá e protegerá o patrimônio cultural brasileiro, por meio de inventários, registros, vigilância, tombamento e desapropriação, e de outras formas de acautelamento e preservação. (BRASIL, 1988)

Neste sentido Rodrigues (2012, p. 218) assinala: 
O caput do art. 216 rompeu com a tradição do direito constitucional brasileiro ao inserir expressamente na Carta Maior o conceito de patrimônio cultural e o fez de forma muito feliz, abraçando simultaneamente os conceitos de "valor histórico", já que prescreve a proteção de bens individualmente, ou em conjunto desde que "portadores de referência à identidade, à ação, memória dos diferentes grupos formadores da sociedade brasileira" sem exigir que sejam de "valor excepcional" e ainda os de "valor sociológico", eis que consagra a defesa de bens imateriais ao lado dos materiais tradicionais.

Ao incorporar o conceito de patrimônio cultural no art. 216, caput, da Constituição da República de 1988, o legislador originário excluiu "acertadamente a necessidade do tombamento prévio, já que seu texto não exige que os bens sejam tombados para integrarem o patrimônio cultural" (RODRIGUES, 2012, p. 218). Ou seja, a qualificação do bem ou conjunto de bens como patrimônio cultural se faz pela existência de características próprias, e não mais condicionados ao procedimento de tombamento.

Observa-se, portanto, tratar-se de um conceito amplo, pois as normas lhes dão significado e abrangência; diversificado, dada a variação de acordo com o diploma legal; aberto e em mutação, já que se sujeita às realidades históricas mutáveis, desenvolvendo-se de maneira progressiva e influenciado pelas exigências de valorização e proteção vindicadas pela sociedade (GOMES, 2013). Nessa mesma linha, Paulo Affonso Leme Machado, assinala que o conceito de patrimônio cultural sistematizado pela Constituição da República de 1988 "é dinâmico, caminha no tempo unindo gerações. É uma noção ampla, e que poderíamos chamar de patrimônio cultural social nacional" (MACHADO, 2016, p. 1123, grifos no original).

Sob esta ótica, o patrimônio cultural arquitetônico pode ser compreendido como qualquer edificação ou estrutura que reflita a identidade, a memória, os valores de uma cidade ou localidade. Ao caracterizar essas estruturas como patrimônio cultural, são reconhecidos marcos referenciais da ocupação do espaço urbano, padrões construtivos, tipológicos e estéticos na construção da identidade de uma sociedade. É, portanto, a partir da salvaguarda do patrimônio cultural, por meio da identificação dos elementos referenciais culturais que cada geração reconstrói à sua maneira o passado:

[...]construindo um mito das origens, descobre pais ancestrais, elege seus heróis fundadores, identifica um patrimônio, cataloga monumentos, transforma espaços em lugares com significados. Mais do que isso, tal processo imaginário de invenção da cidade é capaz de construir utopias, regressivas ou progressivas, através das quais a urbs sonha a si mesma. (PESAVENTO, 2002, p. 25)

Conforme Nascimento et al. (2015, s.p), o patrimônio cultural "é responsável pela continuidade histórica de uma comunidade que se reconhece como tal e corporifica seus ideais 
e valores transcendendo as gerações". As estruturas culturais arquitetônicas consistem em "importantes fatores de coesão social, de orientação e reconhecimento, sem os quais a estabilidade psíquica e os valores existenciais de cada um não existiriam" (NASCIMENTO et al., 2015, s.p.).

Além de revelar padrões construtivos, elementos estilísticos, o patrimônio cultural arquitetônico permite a reconstrução idealizada da paisagem urbana, a perpetuação da memória da cidade, assim como as dos próprios indivíduos que fundaram na urbs suas identidades (REIS\&FONSECA, 2016). E, por meio da percepção do patrimônio cultural edificado o indivíduo experimenta a cidade como cultura, como espaço de ideias, valores e costumes.

Ao consignar a proteção do patrimônio cultural brasileiro, a Constituição da República de 1988, em seu art. 216, determinou a colaboração entre o Poder Público e a sociedade, alçando esta última ao status de coadjuvante na salvaguarda dos bens culturais, conferindo-Ihe uma atuação ativa. Dentre as formas de acautelamento do patrimônio cultural arquitetônico prevista no art. 216, §1ํㅡ, o tombamento é o clássico instrumento utilizado na proteção dos bens culturais imobiliários. No entanto, há casos em que essa proteção não se mostra efetiva, pois em decorrência da limitação à fruição do direito de propriedade, muitos imóveis são demolidos, depredados e abandonados pelos próprios proprietários, inviabilizando a preservação ou a restauração dos bens, numa tentativa de reverter o ato de tombamento. Além das limitações ao direito de propriedade, os proprietários dos imóveis tombados devem suportar os custos para sua manutenção e preservação, e, muitas vezes, sentem-se usurpados em seu direito de propriedade.

Assim, ante as limitações ao direito de propriedade e o dever de preservação, manutenção e proteção decorrentes do instituto do tombamento, buscou-se por meio de medidas compensatórias mitigar os custos financeiros, bem como compensar o proprietário pela limitação ao uso da propriedade. No decorrer deste estudo, serão analisadas as medidas compensatórias de isenção de imposto predial e territorial urbano (IPTU), a transferência do direito de construir e o programa "Adote um bem cultural" no âmbito do município de Belo Horizonte. 


\section{POLÍTICA URBANA E AS MEDIDAS DE INCENTIVO À PROTEÇÃO DO PATRIMÔNIO CULTURAL ARQUITETÔNICO}

Neste tópico, analisar-se-á a proteção do patrimônio cultural como diretriz urbanística, prevista no Estatuto da Cidade, cumprindo o preceito constitucional constante no art. 182, que trata da política urbana. No âmbito do município de Belo Horizonte, o Plano Diretor estabeleceu diretrizes de proteção da memória e do patrimônio cultural, harmonizando-as ao texto constitucional e ao Estatuto da Cidade. Dentre essas, previu como diretriz a compensação dos proprietários de imóveis tombados, em razão dos custos suportados pelos proprietários de edificações tombadas e do esvaziamento econômico desses bens.

Medidas compensatórias, como a isenção de Imposto Predial e Territorial Urbano (IPTU) e a Transferência do Direito de Construir, visam tem como escopo incentivar a preservação do patrimônio cultural e mitigar o desequilíbrio dos encargos experimentados por aqueles proprietários em relação aos demais cidadãos. Essas medidas serão investigadas a seguir.

\section{A proteção do patrimônio cultural como diretriz urbanística}

A Constituição da República, de 1988, sistematizou, em seu art. 182, a política de desenvolvimento urbano a ser executada pelo Poder Público municipal, conforme diretrizes gerais fixadas em lei, tendo como objetivo "ordenar o pleno desenvolvimento das funções sociais da cidade e garantir o bem-estar de seus habitantes" (BRASIL, 1988, s.p.).

Em cumprimento à norma constitucional e atendendo às disposições constantes nos arts. 21, XX e 24, I, cumulado com o $\$ 1^{\circ}$ da Constituição da República, de 1988, que determina a instituição de normas gerais de desenvolvimento urbano, o Estatuto da Cidade - Lei $\mathrm{n}^{\circ}$ 10.257/01, veio suprir a lacuna legislativa até então existente, estabelecendo, em seu art. $2^{\circ}$, as diretrizes da política urbana "com o objetivo expresso de ordenar o pleno desenvolvimento das funções sociais da cidade e da propriedade urbana" (MIRANDA, 2012, p. 270).

Dentre as diretrizes urbanísticas, o inciso XII, do art. $2^{\circ}$ do Estatuto da Cidade determinou a "proteção, preservação e recuperação do meio ambiente natural e construído, do patrimônio cultural, histórico, artístico, paisagístico e arqueológico" (BRASIL, 2001, s.p.). Embora esses deveres já constem no texto constitucional, especificamente nos arts. 23, III e IV, 216 e 225, a existência dessa diretriz terá importante repercussão no âmbito jurídico. 
Essa implicação se refere ao "efeito vinculante e impositivo do postulado, que se constitui norma geral, de observância obrigatória, nos termos do art. $24 \S 1^{\circ}$ e 30, I, II, III da $\mathrm{CF} / 88$, no que tange à competência legislativa dos Estados e Municípios sobre matéria urbanística" (MIRANDA, 2012, p. 270). Significa que a proteção, preservação e recuperação do patrimônio cultural constituem princípios de observância obrigatória na elaboração de legislações urbanísticas.

No âmbito do município de Belo Horizonte, as regras urbanísticas constantes no Plano Diretor ${ }^{2}$, assim como na lei de Uso e Ocupação do Solo e demais regramentos urbanísticos, devem estar em harmonia com a diretriz, prevista no art. $2^{\circ}$, XII do Estatuto da Cidade. Na hipótese de existência de normas contrárias a esse postulado, essas poderão ser questionadas judicialmente.

Dentre as diretrizes que orientam a proteção da memória e do patrimônio cultural, fixadas no art. 15 do Plano Diretor do município de Belo Horizonte, destaca-se a prevista em seu inciso VII, a qual determina a compensação dos proprietários de bens protegidos. Essa compensação poderá ocorrer com a isenção de IPTU, assim como pela Transferência do Direito de Construir, as quais se passa a análise.

\section{Isenção de Imposto Predial e Territorial Urbano no município de Belo Horizonte}

A isenção de IPTU consiste numa das medidas compensatórias, promovidas pelo município de Belo Horizonte, prevista na lei municipal n $5.839 / 90$, em seu art. $9^{\circ}$, que dispõe:

Art. 9o Fica isento do Imposto sobre a Propriedade Predial e Territorial Urbana - IPTU - o imóvel tombado pelo Município por meio de deliberação de seus órgãos de proteção do patrimônio histórico, cultural e artístico, sempre que mantidos em bom estado de conservação.

Parágrafo Único - A isenção do imposto poderá ser estendida a bens imóveis tombados por órgãos de proteção do patrimônio histórico, cultural e artístico do Estado de Minas Gerais ou da União, desde que o tombamento seja ratificado pelos órgãos de que trata o caput deste artigo.

\footnotetext{
${ }^{2}$ Ver Plano Diretor do município de Belo Horizonte - 7.165, de 27 de agosto de 1996, especificamente o art. $1^{\circ}$, que o define como instrumento básico de política de desenvolvimento urbano; o art. 3, I, VI, que estabelece a função social da propriedade e a preservação, proteção e recuperação do patrimônio cultural como objetivos do Plano Diretor; o art. $4^{\circ}$, que trata das diretrizes de uso e ocupação do solo urbano; art. $7^{\circ}, \mathrm{XII}$ e XVI, que define os objetivos estratégicos que visam à melhoria da qualidade de vida no munícipio, destacando-se esses incisos privilegiarem a proteção e promoção do patrimônio cultural; e o art. 15, que dispõe sobre as diretrizes de proteção da memória e do patrimônio cultural.
} 
Conforme o referido dispositivo, os imóveis tombados por quaisquer instituições responsáveis pela proteção do patrimônio cultural, como o Instituto do Patrimônio Histórico e Artístico Nacional (IPHAN), o Instituto Estadual do Patrimônio Histórico e Artístico de Minas Gerais (IEPHA/MG) ou o Conselho Deliberativo do Patrimônio Cultural do Município de Belo Horizonte (CDPCM-BH), poderão obter isenção de IPTU. Entretanto, essa isenção não é concedida de forma automática, sendo necessária a obtenção de "laudo favorável sobre as condições da sua manutenção e proteção" (FRATTARI \& PIANCÓ, 2010, p. 252), expedido pela Diretoria de Patrimônio Cultural da Fundação Municipal de Cultura. A isenção tributária está condicionada à conservação das características culturais que justificam o tombamento do bem.

A isenção de IPTU tem como finalidade compensar os custos de manutenção e conservação das edificações tombadas. Contudo, esses custos muitas vezes superam o valor compensado, por meio da isenção tributária, demandando dos proprietários de imóveis tombados o financiamento de sua preservação.

Em pesquisa realizada por Botelho \& Andrade (2005), na qual se avaliaram o conhecimento e opinião acerca da política municipal de tombamento, foram entrevistados 78 proprietários de edificações tombadas. Quando perguntados espontaneamente sobre incentivos municipais, 44\% responderam conhecer a isenção de IPTU; quando estimulados, esse percentual subiu para $75 \%$ dos entrevistados, contudo, apenas 26,6\% usufruíam dessa isenção. $\mathrm{Na}$ mesma pesquisa, dos proprietários cientes da isenção tributária, 62\% a avaliaram positivamente, enquanto 38\%, negativamente. Esses últimos consideraram o processo para requerimento da isenção burocrático, demorado e apontaram como problema o fato de que seu requerimento deve ser feito anualmente (BOTELHO \&ADNRADE, 2005, s.p.).

A isenção de IPTU emerge como um mecanismo de equalização entre os proprietários de edificações culturais e os demais indivíduos. Entretanto, essa compensação ainda é insatisfatória em relação aos imóveis que apresentam um baixo valor venal e, por consequência, um baixo valor do IPTU. Desse modo, outro mecanismo, como a Transferência do Direito de Construir, poderá fornecer um aporte financeiro maior para a preservação do patrimônio cultural. 


\section{Transferência do Direito de Construir}

\section{Direito de construir}

Conforme Gasparini (2005, p. 71), o direito de construir "sempre foi considerado como uma consequência lógica do direito de propriedade ${ }^{3 \prime}$, ou seja, a decisão de como, quando e o que construir no imóvel era uma exclusividade do proprietário, que deveria observar as limitações prescritas na legislação civil quanto ao direito de vizinhança (GASPARINI, 2005). Embora amplo, o direito de construir não é absoluto e sofre limitações, com vistas à harmonização do convívio social, já que repercutirá nas relações de vizinhança.

A edificabilidade, segundo Silva (2012, p. 81), "não é algo natural aos terrenos"." Essa surge a partir da ordenação do solo urbano - "é algo novo, acrescido, criado pelos planos e normas urbanísticos, por mais elementares que sejam. Edificabilidade é qualificação legal que se atribui a algum terreno urbano" (SILVA, 2012, p. 81) e que permite ao proprietário o exercício da faculdade do direito de construir em solo urbano.

Ao abordar o tema direito de construir ou, mais especificamente, o "direito de edificar em solo urbano", o texto do art. 1.229 do Código Civil deverá ser interpretado, observando-se "as transformações não só da realidade urbana, mas especialmente das normas constitucionais sobre o regime de propriedade ${ }^{5 "}$ (SILVA, 2012, p. 81).

A Constituição da República de 1988, ao dispor sobre o direito de propriedade, condicionou o seu exercício ao atendimento da sua função social (art. 5, XXIII, CR/88), ou seja, o direito propriedade não servirá a fins exclusivamente privatísticos, de caráter individualista, mas deverá voltar-se ao bem-estar coletivo.

No intento de proteger o patrimônio cultural edificado, o direito de construir sofrerá limitações, de forma a atender ao preceito constitucional da função social da propriedade. Na

\footnotetext{
${ }^{3} \mathrm{O}$ direito de propriedade está previsto no art. 1.228 do Código Civil, de 2002, que o define como a "faculdade de usar, gozar e dispor da coisa, e o direito de reavê-la do poder de quem quer que injustamente a possua ou detenha". $\mathrm{O} \S 1^{\circ}$ do citado dispositivo determina que o direito de propriedade "deverá ser exercido em consonância com as suas finalidades econômicas e sociais e de modo que sejam preservados, de conformidade com o estabelecido em lei especial, a flora, a fauna, as belezas naturais, o equilíbrio ecológico e o patrimônio histórico e artístico, bem como evitada a poluição do ar e das águas". Depreende-se do $\S 1^{\circ}$ do art. 1.228 que o direito de propriedade está condicionado ao atendimento da sua função social e limitado à preservação de bens ambientais, dentre os quais está compreendido o patrimônio cultural.

${ }^{4}$ Para José Afonso da Silva (2012, p. 81), o que é natural aos terrenos é a produção de riquezas naturais.

5 Ver art. $5^{\circ}$, XXII, XXIII; art. 182, os quais tratam, respectivamente, do direito de propriedade condicionado à sua função social e da política urbana.
} 
medida em que uma edificação de interesse cultural é protegida, preservada e conservada, tem-se a efetivação do preceito fundamental da função social da propriedade.

\section{Transferência do Direito de Construir}

Em razão das restrições impostas ao proprietário de edificação tombada e do esvaziamento econômico do bem, a Transferência do Direito de Construir emerge como medida compensatória a esse proprietário.

O instituto da Transferência do Direito de Construir integrou o ordenamento jurídico brasileiro a partir da Lei no 10.257, de 10 de julho de 2001 - Estatuto da Cidade, previsto em seu artigo 4으, inciso V, alínea "o". Conforme esse dispositivo, serão utilizados instrumentos de política urbana, assim como mecanismos jurídicos e políticos, dentre os quais se encontra a Transferência do Direito de Construir:

Art. 4 Para os fins desta Lei, serão utilizados, entre outros instrumentos:

$[\ldots]$

$\checkmark$ - institutos jurídicos e políticos:

$[\ldots]$

o) transferência do direito de construir;

A Transferência do Direito de Construir pode ser compreendida como a transmissão do potencial construtivo remanescente de uma edificação para outro imóvel, localizada em área previamente definida pela legislação municipal. A Transferência do Direito de Construir tem por finalidade a compensação pela perda do valor econômico do bem, uma vez que os bens culturais estão sujeitos a um regime particular quanto à sua proteção. Nesse sentido, Miranda disserta:

Esse instrumento tem sido utilizado, com frequência, como uma forma de compensar o proprietário de imóvel tombado que não pode ampliá-lo ou demoli-lo para no local realizar construção moderna e com número elevado de pavimentos. Assim, contribui para a justa repartição dos encargos, ônus e benefícios decorrentes da aplicação do regime de proteção e valorização do patrimônio cultural. (MIRANDA, 2012, p. 279)

Assim, o proprietário que não puder exercer plenamente o direito de construir, em virtude das limitações que pretendem a proteção do patrimônio cultural, "poderá ser beneficiado da transferência do direito de construir, que Ihe possibilita utilizar em outro local ou mesmo alienar esse direito, de acordo com previsão em lei municipal baseada no plano diretor" (MIRANDA, 2012, p. 279) (Figura 4). 
Figura 1. Transferência do potencial construtivo de uma unidade para uma receptora.

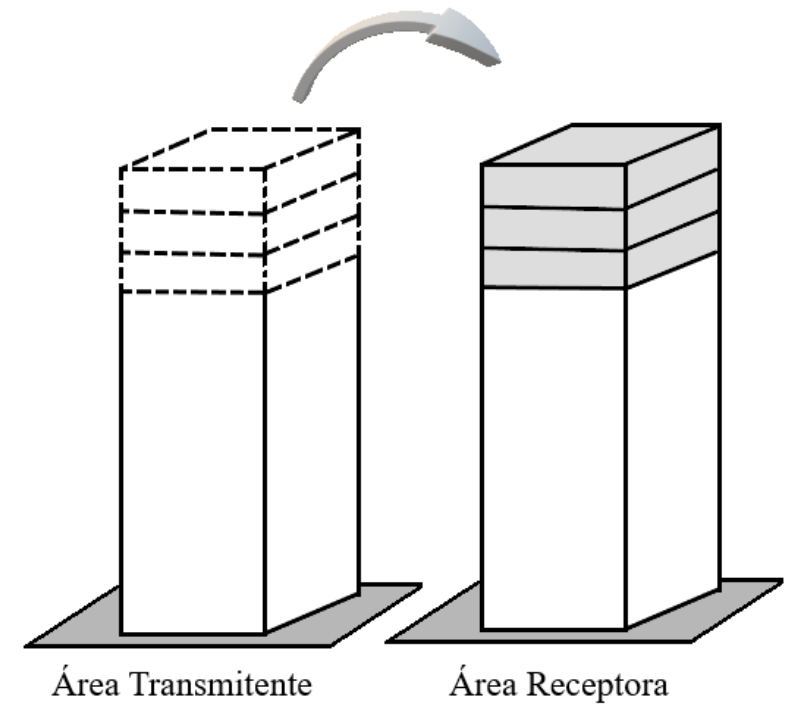

Trata-se de uma faculdade que poderá ser concedida a proprietário de imóvel urbano, privado ou público, quando este preencher um dos requisitos prescritos nos incisos de I a III, do art. 35, do Estatuto da Cidade:

Art. 35. Lei municipal, baseada no plano diretor, poderá autorizar o proprietário de imóvel urbano, privado ou público, a exercer em outro local, ou alienar, mediante escritura pública, o direito de construir previsto no plano diretor ou em legislação urbanística dele decorrente, quando o referido imóvel for considerado necessário para fins de:

I - implantação de equipamentos urbanos e comunitários;

II - preservação, quando o imóvel for considerado de interesse histórico, ambiental, paisagístico, social ou cultural;

III - servir a programas de regularização fundiária, urbanização de áreas ocupadas por população de baixa renda e habitação de interesse social.

$\S 1$ 으 A mesma faculdade poderá ser concedida ao proprietário que doar ao Poder Público seu imóvel, ou parte dele, para os fins previstos nos incisos I a III do caput.

$\S 2$ 2 A lei municipal referida no caput estabelecerá as condições relativas à aplicação da transferência do direito de construir.

A partir da análise do referido dispositivo, denota-se que o interesse público a fundamentar a Transferência do Direito de Construir está vinculado às três hipóteses expressas no Estatuto da Cidade que, como norma geral de direito urbanístico, apresenta as diretrizes e as finalidades da Transferência do Direito de Construir "que não poderão ser transbordados nem inobservados pela legislação municipal" (FRANCISCO, 2001, p. 228). 
Do caput, apreende-se também o reconhecimento, pelo Estatuto da Cidade, da "autonomia do direito de construir em relação ao direito de propriedade" (GASPARINI, 2005, p. 78), contudo a transferência somente poderá ser exercida, se cumprir um dos objetivos constantes no Estatuto da Cidade (GASPARINI, 2005).

As condições a serem apresentadas pelos imóveis para que haja a possibilidade de Transferência do Direito de Construir estão previstas nos incisos do art. 35 do Estatuto da Cidade. De acordo com esse dispositivo, o imóvel cujo potencial construtivo possa ser transferido deverá atender ao interesse público para assentamento ou implantação de equipamentos urbanos ou para preservação de imóveis, em razão das características ambientais, paisagísticas, sociais, culturais e históricas. Em decorrência desse condicionamento às exigências constantes nos incisos I, II e III do art. 35, não é possível pensar a transferência do potencial construtivo cuja finalidade não esteja prevista no Estatuto da Cidade. Assim, norma municipal não poderá prever hipóteses que extrapolem aquelas definidas pelo Estatuto da Cidade, tendo em vista que a competência para legislar sobre normas gerais de direito urbanístico é privativa da União (art. 24, I e $\S 1^{\circ}$, da CR/88).

Ao condicionar a Transferência do Direito de Construir àquelas exigências, "reforça-se ainda mais o cumprimento da função social da propriedade, uma vez que não é qualquer proprietário que poderá vender o direito de construir de seu imóvel com objetivos meramente especulativos" (GASPARINI, 2005, p. 79). Ou seja, a possibilidade de transferência do potencial construtivo será aceitável, quando os imóveis cumprirem sua função social. Segundo Gasparini (2005, p. 79), a transferência livre do direito de construir - sem aquelas limitações previstas nos incisos do art. 35, culminaria por "gerar imóveis desprovidos de capacidade para que a função social da propriedade fosse cumprida, uma vez que sobre eles, não seria possível, em tese, construir" (GASPARINI, 2005, p. 79).

Para que a transferência possa ser utilizada como instrumento de política urbana, é imprescindível a existência de legislação municipal, disciplinando sua aplicação, pois "somente o município tem condições de dimensionar a necessidade de sua aplicação e ainda, qual região de seu território tem equipamentos urbanos necessários para receber um maior adensamento" (GASPARINI, 2005, p. 80). Ao município, compete o planejamento da distribuição da população no território, evitando a superpovoação e baixo adensamento de suas áreas urbanas, equilibrando, consequentemente, o uso de seus equipamentos públicos. 


\section{Transferência do Direito de Construir no município de Belo Horizonte}

Em Belo Horizonte, a Transferência do Direito de Construir tem sido utilizada antes mesmo da edição do Estatuto da Cidade. A lei municipal no 7.165, de 27 de agosto de 1996 Plano Diretor do município de Belo Horizonte, no art. 15, IV sistematiza as diretrizes de proteção da memória e do patrimônio cultural, dentre as quais figura a Transferência do Direito de Construir:

Art. 15 - São diretrizes de proteção da memória e do patrimônio cultural: $[\ldots]$

IV - adotar medidas visando à manutenção dos terrenos vagos lindeiros a mirantes, mediante incentivos fiscais, desapropriação ou transferência do direito de construir

Já o art. 60 do Plano Diretor traz a definição do instituto e o meio pelo qual se transfere o direito de construir, em consonância ao art. 35 do Estatuto da Cidade. De acordo com esses dispositivos, o meio pelo que se perfaz a transferência é a escritura pública:

Art. 60 - Transferência do Direito de Construir - TDC - é o instrumento pelo qual o Poder Público Municipal autoriza o proprietário de imóvel urbano a alienar ou a exercer em outro local, mediante escritura pública, o direito de construir previsto na Lei de Parcelamento, Ocupação e Uso do Solo relativo ao Coeficiente de Aproveitamento Básico - CAb -, observado o disposto no art. 61 desta Lei.

Embora o Estatuto tenha sido silente quanto à necessidade de averbação da Transferência do Direito de Construir na matrícula imobiliária, o decreto municipal n 15.625 , de 22 de julho de 2014, alterou o art. 12 do decreto no 15.254/13, que passou a dispor:

Art. 12 Cabe ao proprietário de imóvel gerador, obrigatoriamente, as averbações das Certidões de Transferência do Direito de Construir emitidas, referentes à constituição do imóvel como gerador de Transferência do Direito de Construir e ao esgotamento do saldo gerador, no respectivo Cartório de Registro de Imóveis.

Conforme o mencionado artigo, o proprietário do imóvel gerador do potencial construtivo está obrigado às averbações das certidões de Transferência do Direito de Construir. Tal medida visa dar publicidade, de modo que futuros adquirentes conheçam a situação em que se encontram os imóveis. O decreto no 15.254_ de 04 de julho de 2013, tratou da Transferência do Direito de Construir no município de Belo Horizonte, disciplinando sobre os imóveis geradores da transferência do potencial construtivo, os receptores, o saldo de área líquida transferível ${ }^{6}$, o cálculo dessa área, dentre outras disposições. Dentre os imóveis geradores da

\footnotetext{
${ }^{6}$ De acordo com o art. 9 do decreto 15.254/13, o saldo de área líquida transferível corresponde até 50\% (cinquenta por cento) do potencial construtivo não exercido no terreno de origem, conforme previsão do $\S 1$ 으, do art. 191, da Lei Orgânica do Município.
} 
Transferência do Direito de Construir, estão compreendidos os imóveis tombados ou incluídos em conjuntos protegidos, conforme dispõe o art. 2o do decreto 15.254/13:

Art. $2^{\circ}$ - Os imóveis geradores da Transferência do Direito de Construir são:

$[\ldots]$

III - os tombados ou incluídos em conjuntos protegidos, impossibilitados de exercer o pleno potencial construtivo definido pelos parâmetros urbanísticos do Plano Diretor e da Lei de Parcelamento, Ocupação e Uso do Solo, em consequência de restrição adicional definida pelo conselho Deliberativo do Patrimônio Cultural do Município de Belo Horizonte $\mathrm{CDPCMBH}$

A partir da investigação desse dispositivo, é possível compreender que a possibilidade de transferência do potencial construtivo de imóveis inseridos em conjuntos protegidos objetiva a proteção do entorno do patrimônio cultural, por meio da compensação pela perda do valor econômico do bem, ainda que esse não seja de interesse cultural.

Entretanto, a Transferência do Direito de Construir, na hipótese do inciso III, exige uma contrapartida do proprietário, assim como será atestada mediante laudo técnico, conforme prevê o $\S 2^{\circ}$ do art. $2^{\circ}$ do mesmo decreto. A possibilidade da Transferência do Direito de Construir não é automática, sendo necessário que o imóvel apresente bom estado de conservação:

§2 A Transferência do Direito de Construir referente aos imóveis que se enquadrarem no disposto no inciso III do caput deste artigo é condicionada ao seu bom estado de conservação, atestado por meio de laudo técnico emitido pela Fundação Municipal de Cultura, a ser solicitado a cada emissão de nova certidão de Transferência do Direito de Construir.

Importante destacar que o $\$ 2^{\circ}$ condiciona os imóveis geradores da Transferência de Direito de Construir a um bom estado de conservação. Embora o faça tanto em relação aos imóveis tombados quanto aos inseridos em conjuntos protegidos, razoável seria uma interpretação, no sentido de que aquela conservação implicasse apenas as edificações tombadas, em razão da norma colhida do texto do art. 17 , do Decreto-lei $n^{\circ} 25 / 37$, relativa à imodificabilidade do patrimônio cultural, enquanto que, dos imóveis inseridos em conjuntos protegidos, esta conservação seria verificada, considerando os efeitos previstos no art. 18 Decreto-lei $n^{\circ} 25 / 37$, referentes à proteção do entorno, ou seja, do respeito às condições de visibilidade do patrimônio cultural. 
Quanto aos imóveis receptores, a legislação municipal sistematizou as áreas urbanas ${ }^{7}$ de recepção. O decreto municipal $n^{\circ}$ 15.254/13, em seu art. $5^{\circ}$, combinado com o art. 62 do Plano Diretor do município de Belo Horizonte, definiu a localização daqueles passíveis de recepção da Transferência do Direito de Construir, de modo a equilibrar a ocupação do solo urbano e, por consequência, preservar a funcionalidade dos equipamentos públicos:

Art. $5^{\circ}$ - Os imóveis receptores da Transferência do Direito de Construir são:

I - os definidos no art. 62 da Lei 7.165/96, respeitadas as diretrizes do CDPCM-BH - para os conjuntos urbanos protegidos e para as Áreas de Diretrizes Especiais - $\quad \mathrm{ADEs}^{8}$; II - os inseridos em área de Operação Urbana, na hipótese de previsão expressa em lei específica.

Parágrafo Único. Os imóveis inseridos em ZPAMs ${ }^{9}$, ZPs $^{10}$ e/ou em ADEs de Interesse Ambiental somente poderão funcionar como receptores da Transferência do Direito de Construir após parecer técnico favorável da Secretaria Municipal de Meio Ambiente, aprovado pelo Comam e, se for o caso, após manifestação do CDPCM-BH.

Dentre esses, destacam-se os imóveis situados em conjuntos protegidos, que somente poderão receber a Transferência do Direito de Construir de imóveis situados na mesma zona. Quanto a esses, para autorização da Transferência do Direito de Construir, é necessário aprovação pelo Conselho Deliberativo do Patrimônio Cultural Municipal, conforme $\S 2^{\circ}$ do art. 62, combinado com o art. 52, ambos constantes no Plano Diretor do município de Belo Horizonte, e o art. $5^{\circ}$ do decreto municipal $n^{\circ} 15.254 / 13$.

De acordo com listagem da Prefeitura Municipal de Belo Horizonte (2016), existem no município cerca de 81 imóveis geradores de Transferência do Direito de Construir, os quais representam pouco mais de $10 \%$ do total de imóveis tombados. As causas da tímida utilização da Transferência do Direito de Construir são incertas, mas uma pesquisa aponta para identificação de uma: o seu desconhecimento pelos proprietários de imóveis tombados.

$\mathrm{Na}$ já mencionada pesquisa, realizada por Botelho \& Andrade (2005), dos 78 proprietários de imóveis tombados, quando questionados se conheciam os incentivos concedidos aos proprietários de edificações culturais, 51,4\% responderam conhecê-los e 33,9\%

\footnotetext{
7 Recomenda-se a leitura do artigo $5^{\circ}$, do decreto municipal $n^{\circ}$ 15.254/13; artigos 52 e 62, do Plano Diretor do município de Belo Horizonte - lei no 7.165, de 27 de agosto de 1996, que disporão sobre as áreas de localização dos imóveis receptores e das diretrizes para transferência do direito de construir.

8 Áreas de diretrizes especiais - Ver art. 75 do Plano Diretor de Belo Horizonte.

${ }^{9}$ Zonas de preservação ambiental

${ }^{10}$ Zonas de proteção - as regiões sujeitas a critérios urbanísticos especiais, que determinam a ocupação com baixa densidade e maior Taxa de Permeabilidade, tendo em vista o interesse público na proteção ambiental e na preservação do patrimônio histórico, cultural, arqueológico ou paisagístico. Ver art. $7^{\circ}$ da Lei de Uso e Ocupação do Solo do município de Belo Horizonte - lei n 7.166/96.
} 
disseram que não. Quando perguntados espontaneamente sobre os incentivos, apenas 3,7\% dos entrevistados citaram a Transferência do Direito de Construir. Quando estimulados, o percentual saltou para $24,8 \%$, contudo, nenhum dos entrevistados utilizou a transferência do potencial construtivo.

Embora o instituto da Transferência do Direito de Construir represente um importante instrumento na política de proteção do patrimônio cultural edificado, podendo significar um estímulo econômico ao particular, é fundamental o seu incentivo e sua utilização conjunta com outros mecanismos, a exemplo da isenção de IPTU, a fim de se obter uma efetiva tutela do patrimônio cultural arquitetônico. Trata-se de um mecanismo, cujas condições para efetivação não dependem somente da conservação do bom estado da edificação pelo proprietário, mas de fatores como a permissão legal para a transferência do potencial construtivo, delimitando as áreas de recepção, bem como da existência de demanda construtiva nas áreas receptoras.

\section{Programa Adote um Bem Cultural}

Além das medidas compensatórias, como a isenção de IPTU e a Transferência do Direito de Construir, o município de Belo Horizonte, por meio do decreto 14.107 de 1 o de setembro de 2010, criou o programa "Adote um Bem Cultural", a fim de promover parcerias entre o Poder Público municipal e a sociedade para preservação do patrimônio cultural:

Art. 1ㅇ Fica criado, no âmbito do Município de Belo Horizonte, o Programa Adote um Bem Cultural, destinado a propiciar, à iniciativa privada, a possibilidade de cooperar com o Poder Público na restauração, conservação, salvaguarda e promoção de bens culturais protegidos e instalados nas vias e logradouros públicos ou nas unidades da Fundação Municipal de Cultura.

Parágrafo Único. Os bens culturais de propriedade privada poderão ser adotados mediante inscrição realizada pelo proprietário ou representante legal, na Diretoria de Patrimônio Cultural, mediante preenchimento de formulário próprio.

Ao analisar o artigo 10 do decreto municipal 14.107/2010, observa-se o interesse do Poder Público em estabelecer vias de cooperação com a iniciativa privada para a proteção, preservação e promoção do patrimônio cultural. O programa "Adote um Bem Cultural" representa um avanço na atuação da Administração Pública, na medida em que cede à iniciativa privada espaço para adoção de medidas protetivas do patrimônio cultural. O alcance dessa cooperação se estende tanto aos bens culturais públicos, como os de propriedade privada, estes condicionados à inscrição na Diretoria de Patrimônio Cultural. A inciativa engloba além 
dos bens de natureza material, como os bens culturais imateriais (art. $2^{\circ}$ ), administrados pelo Poder Público municipal.

Conforme o art. 3o do decreto 14.107/2010, serão estabelecidas condições mediante a celebração de termo de cooperação a ser firmado com as pessoas físicas ou jurídicas. A adoção de bem cultural está condicionada à aprovação de solicitação encaminhada pelos interessados à Fundação Municipal de Cultura. Aprovada a solicitação, o termo de cooperação será válido por 2 anos (art. 5o). Destaca-se, ainda, que os termos de cooperação poderão ser firmados por mais de um interessado na adoção de um bem cultural, "desde que haja consenso entre os interessados e sejam formalmente definidas as responsabilidades de cada um, como coparceiros (sic) do Poder Público Municipal" (art. 6º).

Ao adotar um bem cultural, os interessados poderão "contratar empresas especializadas para a conservação do bem cultural objeto do convênio" (art. 7o), assim como fazer publicidade como membro do programa junto ao bem cultural adotado, durante a restauração ou ação periódica de adoção.

Observa-se, portanto, que o programa "Adote um Bem Cultural" constitui um importante instrumento para salvaguarda do patrimônio cultural municipal de Belo Horizonte. Além de promover a preservação, conservação e restauração dos bens culturais com apoio da iniciativa privada, busca a educação da sociedade quanto a necessidade de preservação do patrimônio cultual e o cuidado com a cidade, na busca por um ambiente ecologicamente equilibrado.

\section{CONSIDERAÇÕES FINAIS}

A sistematização da preservação do patrimônio cultural pela Constituição da República de 1988 constitui um marco na salvaguarda dos bens culturais brasileiros. Além de abranger os de natureza material e imaterial, a Constituição da República de 1988 incorporou a ideia de cultura, preterindo a de história, retirando o caráter de excepcionalidade como requisito para caracterização do bem como patrimônio cultural. Atributos como identidade, ação e memória dos grupos que formam a sociedade brasileira passaram a nortear as políticas de proteção bens culturais. O patrimônio cultural arquitetônico revela os ideais, valores, costumes, padrões construtivos, bem como o modo de produção do espaço, de diferentes grupos e regiões diversas. Os bens culturais arquitetônicos permitem a reconstrução do passado e a perpetuação da memória da cidade e dos próprios indivíduos. 
O instituto do tombamento tem sido largamente utilizado na preservação do patrimônio cultural, no entanto, em determinados casos, esse instrumento não se mostra efetivo na proteção dos bens culturais edificados. Alguns proprietários de imóveis tombados, cientes das limitações ao exercício do direito propriedade decorrentes do tombamento, deixam de promover a conservação dos imóveis, os depredam, demolem, com o objetivo de inviabilizar a restauração desses bens. Além da limitação ao direito de propriedade, os custos de manutenção e restauração dos imóveis são um desestímulo à preservação do imóvel tombado.

Nessa perspectiva, medidas compensatórias como a isenção de Imposto Predial e Territorial Urbano (IPTU) e a Transferência do Direito de Construir surgem como estímulo econômico à preservação do patrimônio cultural. O município de Belo Horizonte, além de instituir a isenção de IPTU, por meio da lei municipal no 7.165, de 27 de agosto de 1996 - Plano Diretor, sistematizou a Transferência do Direito de Construir, antecipando-se ao Estatuto da Cidade.

Daqueles instrumentos, a isenção de IPTU é a mais conhecida e requerida pelos proprietários de edificações tombadas. Contudo, em determinados casos a isenção tributária é insatisfatória, em razão do baixo valor venal atribuído ao imóvel e, por consequência, o IPTU não é suficiente para suportar os gastos com a manutenção do bem cultural. A Transferência do Direito de Construir surge como um mecanismo de estímulo aos proprietários de edificações tombadas. A transação do direito de construir pode gerar um aporte financeiro maior, contribuindo para a conservação ou restauração do imóvel, bem como compensar financeiramente o proprietário pela limitação ao exercício do direito de propriedade.

Noutra perspectiva, o programa "Adote um Bem Cultural" é uma iniciativa de gestão colaborativa do patrimônio cultural do município de Belo Horizonte. Por meio dessa é permitida à iniciativa privada a adoção de bens culturais, tanto os de natureza material como imaterial, atuando ativamente na preservação, restauração e promoção do patrimônio cultural. A medida criada pelo Poder Público, além de ampliar a salvaguarda do acervo cultural, possibilita a inserção e promoção de uma cultura preservacionista e cuidado com o ambiente urbano.

Como demonstrado por Botelho \& Andrade (2005), apenas 3,7\% dos entrevistados responderam, espontaneamente, conhecer a Transferência do Direito de Construir. Entretanto, nenhum dentre os entrevistados utilizou a transferência do potencial construtivo. Além da implementação de instrumentos que potencializem a preservação do patrimônio cultural, a exemplo de Belo Horizonte, é fundamental garantir o acesso à informação e orientação, a fim de que essas medidas sejam adotadas pelos proprietários de edificações culturais. 


\section{REFERÊNCIAS}

BELO HORIZONTE. Lei n. 3.802 de 06 de julho de 1984. Organiza a proteção do patrimônio cultural do município de Belo Horizonte. Disponível em: <https://ecphm.pbh.gov.br/pbh/ecp/files.do?evento=download\&urlArqPIc=Lei_3802-

84_Patrimonio_Cultural.pdf>. Acesso em: 16 maio 2018.

BELO HORIZONTE. Lei 5.839, de 28 de dezembro de 1990. Procede à reavaliação das isenções, incentivos e benefícios fiscais, de acordo com o art. 21 do ato das disposições constitucionais transitórias da lei orgânica do município de Belo Horizonte. Disponível em: <https://www.cmbh.mg.gov.br/atividade-legislativa/pesquisar-legislacao/lei/5839/1990>. Acesso em: 16 maio 2018.

BELO HORIZONTE. Lei 7.165, de 27 de agosto de 1996. Plano Diretor do Município de Belo Horizonte. Disponível em: <https://prefeitura.pbh.gov.br/sites/default/files/estrutura-degoverno/politica-urbana/Lei_7165_Plano_Diretor.pdf>. Acesso em 16 maio 2018.

BELO HORIZONTE. Decreto 14.107 de 1 o de setembro de 2010. Cria o Programa Adote um Bem Cultural. Disponível em: <https://leismunicipais.com.br/a/mg/b/belohorizonte/decreto/2010/1411/14107/decreto-n-14107-2010-cria-o-programa-adote-um-bemcultural-no-ambito-do-municipio-de-belo-horizonte-e-estabelece-normas-e-procedimentospara-parcerias-entre-o-poder-publico-municipal-e-a-sociedade-no-que-concerne-a-adocao-debens-culturais-e-da-outras-providencias>. Acesso em: 13 jun. 2018.

BELO HORIZONTE. 15.254, de 04 de julho de 2013. Dispõe sobre a Transferência do Direito de Construir. Disponível em: <https://leismunicipais.com.br/a/mg/b/belohorizonte/decreto/2013/1525/15254/decreto-n15254-2013-dispoe-sobre-a-transferencia-dodireito-de-construir>. Acesso em: 16 maio 2018.

BELO HORIZONTE. Decreto no 15.625, de 22 de julho de 2014. Altera o decreto no 15.254/13. Disponível em: <https://leismunicipais.com.br/a/mg/b/belohorizonte/ decreto/2014/1562/15625/decreto-n-15625-2014-altera-o-decreto-n-15254-2013>. Acesso em: 16 maio 2018 
BRASIL. Decreto-Lei no 25, de 30 de novembro de 1937. Disponível em: <http://www.planalto.gov.br/ccivil_03/decreto-lei/Del0025.htm>. Acesso em: 15 maio 2018.

BRASIL. Constituição da República do Brasil, de 1988. Disponível em: <http://www.planalto.gov.br/ccivil_03/Constituicao/Constituicao.htm>. Acesso em: 15 maio 2018.

BRASIL. Estatuto da Cidade. Lei no 10.257, de 10 de julho de 2001. Disponível em: <http://www.planalto.gov.br/ccivil_03/leis/LEIS_2001/L10257.htm.>. Acesso em: 16 maio 2018.

DI PIETRO, Maria Sylvia Zanella. Direito Administrativo. 24 ed. São Paulo: Atlas, 2011.

FRANCISCO, Caramuru Afonso. Estatuto da Cidade Comentado. São Paulo: Juarez de Oliveira, 2001.

GASPARINI, Audrey. Tombamento e Direito de Construir. Belo Horizonte: Fórum, 2005.

GOMES, Enéias Xavier. O Patrimônio Cultural como Direito Fundamental. In: ALMEIDA, Gregório Assagra de; SOARES JÚNIOR, Jarbas; MIRANDA, Marcos Paulo de Souza (Coord.). Patrimônio Cultural. Belo Horizonte: Del Rey, 2013.

MACHADO, Paulo Affonso Leme. Direito Ambiental Brasileiro. 24. ed. rev., ampl. e atual. São Paulo: Malheiros, 2016.

MEIRELLES, Hely Lopes. Direito de Construir. 11. ed. atualizada por Adilson Abreu Dallari; Daniela Libório Di Sarno; Luiz Guilherme da Costa Wagner Jr.; Mariana Novis. São Paulo: Malheiros, 2013.

MIRANDA, Marcos Paulo de Souza. O Estatuto da Cidade e os novos instrumentos urbanísticos de proteção ao patrimônio cultural. In: RODRIGUES, José Eduardo Ramos; MIRANDA, Marcos Paulo de Souza. Estudos de direito do patrimônio cultural. Belo Horizonte: Fórum, 2012. 
MIRANDA, Marcos Paulo de Souza. Lei do Tombamento Comentada. Doutrina, jurisprudência, legislação. Belo Horizonte: Del Rey, 2014.

MOREIRA, Lilian Maria Ferreira Marotta. Patrimônio Cultural Imaterial e sua Proteção pelo Ministério Público. In: ALMEIDA, Gregório Assagra de; SOARES JÚNIOR, Jarbas; MIRANDA, Marcos Paulo de Souza (Coord.). Patrimônio Cultural. Belo Horizonte: Del Rey, 2013.

NASCIMENTO, Fernando P.; MAGALHÃES, Leandro S.; CARSALADE, Flávio L.; CASTRO, Maria A. R.; FONSECA, Bárbara S.; RAIMAR, Cassiano S.; BERNARDO, Marcus V. A. F. R.; PERET, Bárbara.; RIBEIRO, Bianca C. Guia online de bens tombados de Belo Horizonte: Procedimentos para a promoção de um acesso público eficiente. Disponível em: <http://www.forumpatrimonio.com.br/arqdoc2015/artigos/pdf/398.pdf>. Acesso em: 15 maio 2018.

PESAVENTO, Sandra Jatahy. Memória, história e cidade: lugares no tempo, momentos no espaço. ArtCultura, Uberlândia, vol. 4, n. 4, 2002.

PIRES, Maria Coeli Simões. Direito urbanístico, meio ambiente e patrimônio cultural. In: FONSECA, Maria Tereza Dias; PAIVA, Carlos Magno de Souza (Coord.). Direito e Proteção do patrimônio cultural imóvel. Belo Horizonte: Fórum, 2010.

RODRIGUES, José Eduardo Ramos. A Importância e Responsabilidade dos Conselhos Municipais do Patrimônio Cultural. In: RODRIGUES, José Eduardo Ramos; MIRANDA, Marcos Paulo de Souza (Coord.). Estudos de Direito do Patrimônio Cultural. Belo Horizonte: Fórum, 2012.

RODRIGUES, José Eduardo Ramos. Aspectos Polêmicos em torno do Patrimônio Cultural. In: RODRIGUES, José Eduardo Ramos; MIRANDA, Marcos Paulo de Souza (Coord.). Estudos de Direito do Patrimônio Cultural. Belo Horizonte: Fórum, 2012.

Trabalho enviado em 15 de junho de 2018

Aceito em 25 de agosto de 2018

Revista de Direito da Cidade, vol. 11, no 1. ISSN 2317-7721 pp. 216-236 